\title{
Implementing an MSN Nursing Program at a Distance Through an Urban-Rural Partnership
}

\author{
Ksenia Zukowsky, PhD, APRN, NNP-BC \\ Thomas Jefferson University \\ Beth Ann Swan, PhD, CRNP, FAAN \\ Thomas Jefferson University \\ Mary Powell, PhD, CRNP \\ Thomas Jefferson University \\ Anthony J. Frisby, PhD \\ Thomas Jefferson University \\ Foribbatwyer and Phddditional works at: https://jdc.jefferson.edu/nursfp \\ Thomas Jefferson University \\ Part of the Nursing Commons \\ Let us know how access to this document benefits you
}

\section{Recommended Citation}

Zukowsky, PhD, APRN, NNP-BC, Ksenia; Swan, PhD, CRNP, FAAN, Beth Ann; Powell, PhD, CRNP, Mary; Frisby, PhD, Anthony J.; Lauver, PhD, RN, Lori; West, PhD, CNE, RN, Margaret Mary; and Marsella, BA, Alexis, "Implementing an MSN Nursing Program at a Distance Through an UrbanRural Partnership" (2011). College of Nursing Faculty Papers \& Presentations. Paper 44.

https://jdc.jefferson.edu/nursfp/44

This Article is brought to you for free and open access by the Jefferson Digital Commons. The Jefferson Digital Commons is a service of Thomas Jefferson University's Center for Teaching and Learning (CTL). The Commons is a showcase for Jefferson books and journals, peer-reviewed scholarly publications, unique historical collections from the University archives, and teaching tools. The Jefferson Digital Commons allows researchers and interested readers anywhere in the world to learn about and keep up to date with Jefferson scholarship. This article has been accepted for inclusion in College of Nursing Faculty Papers \& Presentations by an authorized administrator of the Jefferson Digital Commons. For more information, please contact: JeffersonDigitalCommons@jefferson.edu. 


\section{Authors}

Ksenia Zukowsky, PhD, APRN, NNP-BC; Beth Ann Swan, PhD, CRNP, FAAN; Mary Powell, PhD, CRNP;

Anthony J. Frisby, PhD; Lori Lauver, PhD, RN; Margaret Mary West, PhD, CNE, RN; and Alexis Marsella, BA 


\title{
As submitted to:
}

\author{
Advances in Neonatal Care
}

\author{
And later published as:
}

\section{Implementing an MSN Nursing \\ Program at a Distance Through an \\ Urban-Rural Partnership}

\section{April 2011 - Volume 11 - Issue 2 - p 114-118}

\section{doi: 10.1097/ANC.0b013e318210d075}

Ksenia Zukowsky, PhD, APRN, NNP-BC; Beth Ann Swan, PhD, CRNP, FAAN;Mary Powell, PhD, CRNP; Tony Frisby, PhD; Lori Lauver, PhD, RN; Margaret Mary West, PhD, CNE, RN; Alexis Marsella, BA

\begin{abstract}
Recruiting, retaining, and educating advanced practice nurses is essential to meet the growing need for advanced practice nurses in rural and urban communities. Through the support of Health Resources and Services Administration funding, the urban school of nursing expanded its MSN program and implemented the graduate curriculum on its rural campus by utilizing emerging online and distance education technologies. The purpose of this manuscript is to provide an overview of expanding an existing MSN program offered in an urban, traditional classroom setting to rural graduate nursing students via an online synchronous format. In addition, the article will describe the rural growth of the existing neonatal nurse practitioner program as an exemplar and the different methodologies that are being used in each program to engage the rural nurse practitioner students in clinical courses. In addition, strategies to address barriers related
\end{abstract}


to rural nurse practitioner student recruitment and retention will be discussed.

KEY WORDS: graduate education, rural education, neonatal nurse practitioner

Recruiting, retaining, and educating advanced practice nurses (APNs) is essential to meet the growing demands for APNs in rural and urban communities. Neonatal nurse practitioners (NNPs) and specialized APNs, who care for sick neonates, are in short supply in both urban and rural heath care facilities. Through the support of Health Resources and Services Administration funding, the urban school of nursing expanded its MSN program tracks and implemented the graduate curriculum on its rural campus by utilizing emerging online and distance education technologies. Before the grant, the school utilized traditional classroom education and asynchronous online methods. With Health Resources and Services Administration funding, the School of Nursing expanded its online portfolio including methods for synchronous online classes, interactive webcasting, and live video over the Internet.

Recruiting and engaging nurses in rural Pennsylvania were the specific focuses of the emerging online and distance education technologies. Nurses now have access to quality graduate nursing education and are able to remain in their communities as APNs. The purpose of this manuscript is to provide an overview of expanding an existing MSN program offered in an urban, traditional classroom setting to rural graduate nursing students via an online synchronous format. In addition, the article will describe the rural growth of the existing NNP program as an exemplar and the different methodologies that are being used in each program to engage the rural nurse practitioner (NP) students in clinical courses. Strategies to address barriers related to rural NP student recruitment and retention will also be discussed.

\section{APN SHORTAGE}

The need for and value of NPs is well documented in the nursing literature, health care literature, and increasingly in the general media. The American Association of Colleges of Nursing in its position statement Nursing Education's Agenda for the $21^{\text {st }}$ Century stated that the future demand for nurses will exceed availability.1 A decade later, Bureau of Labor Statistics2 
support this critical need. As nurses with advanced education take their places as key providers of care in acute and community settings, primary health care, and health promotion services, the demand for APNs will increase.

A critical shortage of APNs exists nationally and in the state of Pennsylvania. In 2005, the highest vacancy rate in Pennsylvania's health care workforce existed, with vacancy rate for APNs at 14.7\%; this is higher than the 2003 vacancy rate of $11.6 \% .3$ The APN vacancy rate in north and central Pennsylvania is higher than the state overall and has risen in the last 5 years. 3 In addition to high vacancy rates, local employees in north and central Pennsylvania report that NNPs are in high demand.

The demand for NPs especially in rural communities, therefore, has markedly expanded as hospitals and integrated delivery systems try to maintain their primary care services and neonatal care services, while providing quality care. The ability to recruit master's prepared NPs is a barrier to patient access and quality primary and neonatal health care. For example, there are many NP positions available within neonatal intensive care units (NICUs) in rural areas. Some of these positions have been vacant for more than a year because of the challenge of finding qualified, master's prepared candidates who desire a practice in rural and/or underserved locations. In addition, there are no other NNP programs in the area.

\section{NNP PROGRAM}

Increasing the numbers of well-prepared NNPs is a critical endeavor regionally and nationally to manage and care for sick and frail neonates. One report of NNP graduates revealed that between 2003 and 2007, NNP graduates had increased to 275 graduates per year (Ensearch Management, November 10, 2009, written personal communication). In 2010, there was a decrease in NNP graduates, from 308 in 2009 to 283 in 2010.4 However, there is a need for 600 to 800 NNPs to fill the current NNP job openings nationally (Ensearch Management, November 10, 2009, personal communication). Beyond this anecdotal information that there is a lack of master's-prepared NNPs to meet the demand, there is no research evidence to date to confirm this perception.5

The perceived shortage has become more evident since "resident" hours in NICUs were decreased in 2003, with NNPs covering these resident hours 
side by side with attending neonatologists. In addition to impacting the need for NNPs, the standards for resident duty hours has also impacted the role of NNPs.6 The role of NNPs now include NICU coverage, teaching, and supervising pediatric residents, while simultaneously being role models for registered nurses and novice NNPs.5,7,8

The lines between medicine and nursing overlap in NICUs. Neonatal intensive care unit staff nurse (registered nurses) place peripheral intravenous and or percutaneous catheters and draw blood, while the NNPs collaborate with the neonatologist to care for the sickest infants in the NICU.9 The advanced practice nursing skills used are parallel to those of the medical staff with some overlap of roles. In addition, NNPs are the frontline providers with expertise in dealing with families in crisis.10 Educating NNPs in the knowledge, skills, and competencies to assume these complex roles in an online environment is challenging.

The urban school of nursing NNP program is a 36- credit MSN curriculum organized around core courses (18 credits), support courses ( 9 credits), and clinical specialty courses ( 9 credits). Before grant funding, all core courses and 1 support course, advanced pathophysiology, were available asynchronously online and in the traditional classroom format. Neonatal pharmacotherapeutics, a second support course, was available asynchronously online only. The third support course, neonatal assessment, and the 3 clinical specialty courses were available only in the traditional classroom format.

In the first year of grant funding, the neonatal assessment course was offered synchronously online since all the NNP students were at a distance.

Synchronous online refers to courses in which the student is required to be online at the same time as the rest of the class or instructor. Asynchronous online refers to courses in which the student is not required to be online at the same time as the rest of the class or instructor. Some online formats have synchronous components to them; for example, students might be "attending" a live guest lecture and able to ask questions back to the speaker. Or they might have online office hours with the faculty for a live one-on-one discussion. Our experience has been that most adult learners prefer an asynchronous format as long as they can still contact the instructor personally when necessary. 
The synchronously online class had the faculty member originating the live webcast from her office computer and the NNP students joined the webcast from their home computers. The faculty for this course made 1:1 appointments with each student at a designated local NICU for demonstration and return demonstrations of eliciting histories and performing neonatal physical examinations. The 3 clinical specialty courses were offered synchronously online as well, with the faculty member originating the live webcast at her office computer and the NNP students joining the webcast from their home computers. Preceptors, both NNPs and neonatologists, were selected on the basis of their credentials, certification (national and state), licensure, and years of clinical experience. Before each student beginning his or her clinical practicum, the NNP program coordinator conducted site visits and interviewed clinical preceptors to evaluate for appropriate clinical placement related to sufficient educational and clinical resources in the practice setting with adequate space and equipment, number, age, and type of clients for the students enrolled in the programs. Neonatal nurse practitioner students' clinical practicum included health care services provided to underserved and minority residents living in rural Pennsylvania, New Jersey, and Delaware. These populations were medically underserved, disadvantaged, lived at or below the poverty line, and had complex health problems. Once students began their clinical practicum, site visits were performed by the NNP program coordinator to develop and assess clinical learning and to support preceptors for teaching, evaluating, and problem solving with NNP students.

The NNP cohort during the second year of the grant included 5 students who could commute to class and 2 distant students who lived within 90 minutes of the campus. The NNP program coordinator requested that all students attend the first clinical course in class. At that time, a joint decision was made to bring the 7 students together in class 2 more times during the semester and then convene via live webcasting for the remainder of the classes. During weeks, when the class did not meet in person, interaction between students and faculty was accomplished through the use of facultyguided weekly threaded discussions, online chat sessions, e-mail, and telephone. Faculty office hours were conducted in both an online and traditional in person format. Additional formative and summative evaluations were solicited related to online delivery periodically throughout the courses. When the class did meet, the 5 local students attended in the traditional classroom setting and 2 students attended via webcasting. The 
students at a distance were able to participate in class, ask questions in real time, and attend class synchronously.

\section{RURAL NP STUDENT RECRUITMENT}

The rural health core grant team established recruitment and enrollment targets as part of the project proposal. The goal was to recruit and retain diverse and disadvantaged students to the MSN program and insure a supply of master's-prepared nurses to offset the APN shortage and primary care provider shortage in rural Pennsylvania. The rural health core team believed that graduates from rural campus would be well positioned to deliver quality, cost-effective, appropriate, and culturally competent care to underserved, vulnerable rural populations identified to be at high risk in national Healthy People 2010 objectives. Although the team was cognizant that different recruitment strategies would be necessary for prospective rural NNP students, the team quickly realized that there were many barriers to student recruitment in rural areas.

\section{BARRIERS TO NNP STUDENT RECRUITMENT}

Disparities in educational status, employment, and income require the development of specialized approaches to rural NP student recruitment and health care service delivery. The rapid population growth in some rural communities may have an impact on available services creating a mix of established residents and new arrivals, with varying expectations on local health and human service delivery systems. On average, incomes are lower in rural Pennsylvania. This fact is illustrated by the adjusted per capita income from federal or state transfer payments, the average household income, the proportion living at or below $200 \%$ of poverty level, and the percentage of households reporting income less than $\$ 25000$ in 1999, which all demonstrate poorer conditions in rural Pennsylvania. Barriers can be overcome by improving recruitment and retention efforts and establishing new clinical learning sites in rural, underserved areas. With this grant funding, emphasis was focused on removing barriers, which limit access to advanced nursing degree education and responded to changing enrollment demands by offering graduate nursing education online and during nontraditional hours.

\section{STRATEGIES TO IMPROVE RURAL NNP STUDENT RECRUITMENT}


An onsite recruiting specialist was one strategy that was planned during the grant-writing process. In addition, in year 1, the Associate Dean for Graduate Programs and the NNP program coordinator made monthly visits and conducted open houses at the rural campus located in Pennsylvania, 150 miles from Philadelphia. In addition, they provided information sessions in a large auditorium, outside the hospital cafeteria, and on patient care units at the change of shifts in the early morning and late afternoon and at lunchtime. This proved to be somewhat effective but did not meet our expectations or recruitment and enrollment targets.

A second strategy that was not realized until the end of year 1 was leveraging the stakeholders who were members of the Rural Health Advisory Board that was formed as one of the activities for the grant. The Rural Health Advisory Board recommended several activities to augment the strategies being used. These activities included meetings with the nurse administrators of rural health care facilities to discuss strategies for engaging nurses in their institutions to consider graduate nursing education. In addition, the rural team members discussed some creative strategies related to tuition reimbursement, practices for future employment, and advancement of careers at their institutions. The rural grant team attended rural meetings and conferences across the state and increased advertising in rural newspapers and other media outlets. All of these activities gave the rural grant team exposure to the critical interface with stakeholders in the state of Pennsylvania.

A third strategy was to meet with rural neonatal physician groups who had a need for NNPs. Following a meeting with the NNP program coordinator, one of the neonatal physician groups in rural Pennsylvania agreed to offer 2 NNP student scholarships. The scholarship package would include a monthly stipend for the nurses throughout the duration of graduate school, payment of the full cost of tuition and fees, and the opportunity for registered nurse pool to work between semesters, if needed. The NNP student scholarship recipients would be required to complete the program in 2 years and sign a 3-year commitment to the group at the rural hospital. The NNP program coordinator would agree to have the student complete one-third of the clinical practicum experience at the tertiary care facility where the neonatology group practices. Other clinical experiences would be completed at other either rural or urban tertiary health care centers. The NNP 
student scholarship recipient would be mentored in their new role, in an environment committed to their success and professional development, with no debt, while attending the program, and with no loans to repay upon graduation. As of fall 2009, there is 1 rural NNP scholarship recipient.

In addition to implementing this strategy with rural neonatal physician groups, a similar model has been successfully implemented in suburban and urban settings. Neonatal practices and/or hospital administration offer incoming NNP students' full tuition for graduate school with a 3-year pay back to the neonatal practice and/or hospital organization.

\section{IMPLICATIONS}

The rural grant had 2 merging objectives or purposes: to provide access to high-quality and rigorous distance education and by doing so, putting qualified NNPs in rural NICUs to improve health care access and delivery of cost-effective, appropriate, and culturally competent care to underserved, vulnerable populations in rural Pennsylvania. These 2 intentions are consistent with Healthy People 2010 objectives: (1) increasing the number and diversity of admissions to existing NNP MSN programs, (2) building a critcritical mass of NNP experts in rural communities, (3) increasing the number of rural sites and preceptors for neonatal practice with underserved populations, and (4) increasing educational experiences aimed toward improving underserved populations quality of care.

Barriers that have been described in this experience as disparities in educational status, employment, and income may have to be overcome to insure the intentions of Healthy People 2010. The American Colleges of Nursing has supported that nurses who are technically competent may need more professional and education growth; a broader knowledge is essential for today's nursing practice. The essential boarder knowledge attributes as creative decision making, critical thinking, management, and finances and to deal with a diverse and multicultural workforce and patient population.11,12 The American Association of Colleges of Nursing recently released a call to action to advocate changes in nursing practice and education, focusing on the importance of academic progression and embrace lifelong learning. Advance practice nurses will need more education and it is necessary for the future to meet the needs in nursing.1,13 Recruiting and engaging nurses in rural Pennsylvania is the specific focus in NNP and other graduate nursing roles as adult, pediatric, family, and 
acute care NP is in accordance with the call nursing policy and standards. The decision to meet the call is the responsibility of the practicing nurse and health care organizations.

\section{Acknowledgments}

The authors thank the Department of Health and Human Services, Health Resources and Services Administration, Bureau of Health Professions, Division of Nursing for the support and funding of this advanced education nursing program, "Promoting Health Access: Online Graduate Programs for Rural Underserved Communities.” D09HP08336-01.

\section{References}

1. American Association of Colleges of Nursing. Nursing Education's Agenda for the 21 st Century; 1999. American Association of Colleges of Nursing. Retrieved from www.aacn..nche..edu/publication/position.nrsge.

2. Bureau of Labor Statistics. 2010 occupational outlook handbook, 2010-11 edition registered nurses. http://www.bls.gov/. Accessed June 13, 2010.

3. Hospital and Healthsystem Association of Pennsylvania. http://www.haponline.org/. Published 2006.

4. Cusson R. State of the science of NNP education. Presented at: the 8th Annual Faculty Forum, APN Faculty Forum, June 2, 2010; Washington, DC.

5. Cusson R, Frank M, Flanagan V, Miller S, Zukowsky K, Rasmussen L. A survey of the current neonatal nurse practitioner workforce. J Perinatol. 2008;28:830-836.

6. Frank JE, Mullaney DM, Darnall RA, Stashwick CA. Teaching residents in the neonatal intensive care unit: a non-traditional approach. $J$ Perinatol. 2000;20(2): 111-113.

7. Juretschke LJ. New standards for resident duty hours and the potential impact on neonatal nurse practitioner role. Adv Neonatal Care. 2003;3:159161. 
8. Little GA, Buus-Frank ME. Transition from house staff in the neonatal intensive care unit: a time to review, revise and reconfirm. Am J Perinatol. 1996;13:127-129.

9. Hawkins JW, Bellig LL. The evolution of advanced practice nursing in the United States: caring for women and newborns. J Obstet Gynecol Neonatal Nurs. 2000;29(1):83-89.

10. Nagle CW, Perlmutter DF. The evolution of the nurse practitioner role in the neonatal intensive care unit. Am J Perinatol. 2000;17(5):225-228.

11. American Association of Colleges of Nursing. Position statement on baccalaureate nursing programs offered by community colleges. http//www.aacn.nche.edu/Publications/positions/ccbsn.htm. Accessed June $10,2010$.

12. Smith T. A policy perspective on the entry into practice issue. Online $J$ Nurs Issues. 2010;15:1.

http://www.nursingworld.org/MainMenuCategories/ANAMarketplace/ANA Periodicals/OJIN/TableofContents/Vol152010/No1Jan2010/ArticlesPrevious-Topic/Policy-and-Entry-into-Practice.aspx. Accessed June 10, 2010.

13. American Association of Colleges of Nursing American Nurses Association, American Organization of Nurse Executives, National League for Nursing. Tricouncil for nursing issues new consensus policy statement on the educational advancement of registered nurses. http://www.aacn.nche.edu/Education/pdf/ TricouncilEdStatement.pdf. Published 2010. Accessed June 10, 2010. 